\title{
El HLA y su implicación en Odontología
}

\author{
Rioboo Crespo M*, Bascones A**, Rioboo García R***
}

\section{RESUMEN}

El sistema HLA constituye uno de los sistemas genéticos más fascinantes del hombre, capaz de codificar una serie de moléculas (moléculas del HLA tipo I y tipo II) presentes en las membranas de la mayoría de las células nucleadas del organismo implicadas en procesos vitales básicos, tales como la respuesta inmunológica , con el fin de mantener la integridad del individuo y de la especie. Considerado inicialmente como un simple marcador genético, los esfuerzos en la búsqueda de su aplicación clínica están a la orden del día asociándose a diversas enfermedades sobretodo autoinmunes o con disfunciones inmunológicas.

En muestro campo, está cobrando cada vez más importancia la posibilidad de que el estudio del HLA nos permita explicar la susceptibilidad, la etiología y la patogénesis de determinadas enfermedades muy frecuentes en la consulta odontológica como la caries, los trastornos temporomandibulares y la enfermedad periodontal, entre otras. Así, los estudios experimentales más actuales se centran en el estudio del HLA para determinar el rol de la respuesta inmune de la pulpa ante determinadas situaciones, investigar una posible vacuna para la caries e incluso averiguar si realmente existe una predisposición genética para el acúmulo de microorganismos orales.

En cuanto al estudio del HLA dentro del campo de los trastornos temporomandibulares, se observa que no solo se ha empleado en la investigación de enfermedades multisistémicas como la Espondilitis Anquilosante o la Artritis Juvenil, sino que se ha demostrado que puede tener utilidad en el campo de la etiopatogénesis de diversas alteraciones temporomandibulares.

Por último, su asociación con las enfermedades periodontales están cobrando cada vez más importancia, aunque se afirme que la susceptibilidad y resistencia de las periodontitis estén influenciadas por determinadas combinaciones de antígenos de HLA, es necesario llevar a cabo un estudio más exaustivo para extraer datos más concluyentes, tema que esperamos realizar en un próximo estudio.

Palabras clave: HLA, CMH, caries, trastornos temporomandibulares, enfermedad periodontal.

\section{ABSTRACT}

The HLA system constitute one of the most fascinated genetic systems of the humans being, able to codificate a grup of molecules (type I and type II HLA molecules) wich are present in most of the organism nucleated celules implicated in vital basic process like the immunologic answer, supporting the individual and specie integrity. Inicially considerated as a simple genetic marker, the search is now applied to a globe placed on the centre of the clinic applications, associated with several diseases, above all, with autoinmune diseases or inmunological disfunctions. For many, the advances stemming from the genome have changed the face of biological investigations and have placed the HLA study at the forefront of determined diseases wich are very frequent in dentistry like caries, temporomandibular disorders or periodontal diseases.

Actuals experimental studies have focused on the HLA study to determinate the role of inmunological response under differents clinical conditions or to investigate possible components of an effective dental caries vaccine or search out the genetic predisposition towards the accumulation of oral microorganism.

In the area of temporomandibular disorders, HLA studies have been employed in multisistemics diseases (juvenil arthritis), but is now demonstrate that the utilization of genetic markers allows the clinical to determine the risk of several temporomandibular disorders. 
There is growing evidence that differences in host response determine susceptibility and resistance to periodontal disease. Diversity of HLA antigen combinations seem to be variable factors in disease associations. However, data from HLA associations is not consistent and further investigations are necessary.

Key words: HLA, CMH, caries, temporomandibular disorders, periodontal diseases.

Aceptado para publicación: Abril 2004.

* Licenciada en Odontología. Becaria para formación de profesorado universitario. Facultad de Odontología UCM.

** Catedrático del departamento III estomatología. Facultad de Odontología UCM.

*** Catedrático del departamento IV estomatología. Facultad de Odontología UCM.

Rioboo Crespo M, Bascones A, Rioboo García R. El HLA y su implicación en Odontología. Av. Odontoestomatol 2005; 21-2: 95-107.

\section{INTRODUCCIÓN}

El complejo mayor de histocompatibilidad (CMH) se conoce en el hombre como sistema HLA (antígeno leucocitario humano, ya que se destinó al principio a "tipificar" únicamente a los leucocitos) y consiste en un conjunto de genes localizado en el cromosoma 6 humano y 17 murino. Tiene una función fundamental en el sistema inmune: la de codificar un grupo de glucoproteinas presentes en las membranas de la mayoría de las células nucleadas del organismo denominadas moléculas HLA $(1,2)$.

La histocompatibilidad consiste literalmente en la capacidad de los tejidos (del griego "histo") para permanecer unidos unos a otros. Se emplea en inmunología para describir los sistemas genéticos que determinan el rechazo de los transplantes de tejidos y órganos, resultado del reconocimiento inmunológico de los antígenos de histocompatibilidad. Así, las moléculas de CMH humano fueron descubiertas originalmente como consecuencia de los intentos de emplear injertos de piel para tratar quemaduras extensas de pilotos y víctimas de bombardeos durante la Segunda Guerra Mundial. Los pacientes rechazaron los injertos que reconocieron como extraños. Pronto se detectó, en estudios realizados por ratones, que el rechazo se debía a una respuesta inmunitaria y experimentos genéticos posteriores permitieron demostrar que el rechazo rápido de los injer- tos de piel era causado por diferencias en loci genéticos únicos. Estos genes se llamaron de "histocompatibilidad", debido al control que ejercían en la compatibilidad de los injertos de tejidos. Mas tarde se demostró que la histocompatibilidad dependía de múltiples genes vecinos, altamente polimórficos, lo que hizo que se denominasen "complejo principal de histomcompatibilidad". De éste modo, fue Jean Dausset quién presentó en 1964 el rol del sistema HLA en los transplantes de órganos y al que premiaron por su labor con el premio Nobel de Medicina en 1980 (3).

Hoy en día, sabemos que el sistema del HLA constituye uno de los sistemas genéticos más fascinantes del hombre. Los progresos alcanzados desde su descubrimiento son impresionantes y ponen de manifiesto el papel que juega éste sistema en el mantenimiento de la integridad del individuo y de la especie. Los esfuerzos en la búsqueda de aplicación clínica están a la orden del día y la mayoría de los componentes de éste sistema han sido asociados a diversas enfermedades.

Cada vez son más los estudios que profundizan en el tema y poco a poco, en nuestro campo, está cobrando cada vez más importancia la posibilidad de que el estudio del HLA nos permita explicar la susceptibilidad, la etiología y la patogénesis de determinadas patologías. 
A lo largo de éste articulo intentaremos, en un primer momento, conocer más a fondo la estructura y función de las moléculas de HLA y daremos un repaso por la literatura en la que se relaciona dicho sistema con determinadas enfermedades bucodentales hasta hoy, poco vinculadas a éste, como la enfermedad periodontal, caries y desórdenes temporomandibulares.

\section{HLA: ESTRUCTURA, GENÉTICA Y FUNCIONES}

\section{A-ESTRUCTURA DE LAS MOLECULAS DEL CMH}

Las moléculas del CMH son glicoproteinas de superficie codificadas por los genes CMH y por tanto presentes en las membranas de la mayoría de las células nucleadas del organismo entre las que se encuentran las células inmunocompetentes.

Existen dos clases de moléculas de CMH que difieren entre sí en cuanto a su estructura y distribución en las células del cuerpo: las moléculas de clase I y las moléculas de clase II. Se diferencian principalmente en cuanto a las subunidades que las componen, pero en cuanto a estructura general los dos tipos de moléculas están muy relacionadas.

\section{> Las moléculas de clase I (fig1)}

Están formadas por dos cadenas polipeptídicas: una cadena a y una cadena $\beta 2$ microglobulina..

La cadena $\alpha$, codificada por el CMH, es mas pesada, de mayor tamaño y la conforman tres subunidades $\alpha 1, \alpha 2$ y $\alpha 3$ unidas entre si por puentes disulfuro. Los dominios $\alpha 1$ y $\alpha 2$ constituyen las paredes de la hendidura en la superficie de la molécula donde se une el péptido, son variables y definen de este modo la especificidad antigénica (polimorfismo).

La cadena $\alpha 3$ es la única transmembrana, es invariable y se asocia a la cadena $\beta$ de forma no covalente.

La cadena $\beta 2$ microglobulina, codificada por el cromosoma 15 (y no por el $\mathrm{CMH}$ ) es más pequeña e invariable (por lo tanto, no polimórfica).

\section{Las moléculas de clase II (fig 1)}

Consiste en un complejo no covalente formado por dos cadenas polipeptídicas $\alpha$ y $\beta$, ambas transmembrana. La cadena $\alpha$ está constituida por los dominios $\alpha 1$ y $\alpha 2$ y la cadena $\beta$ por los dominios $\beta 1$ y $\beta 2$.

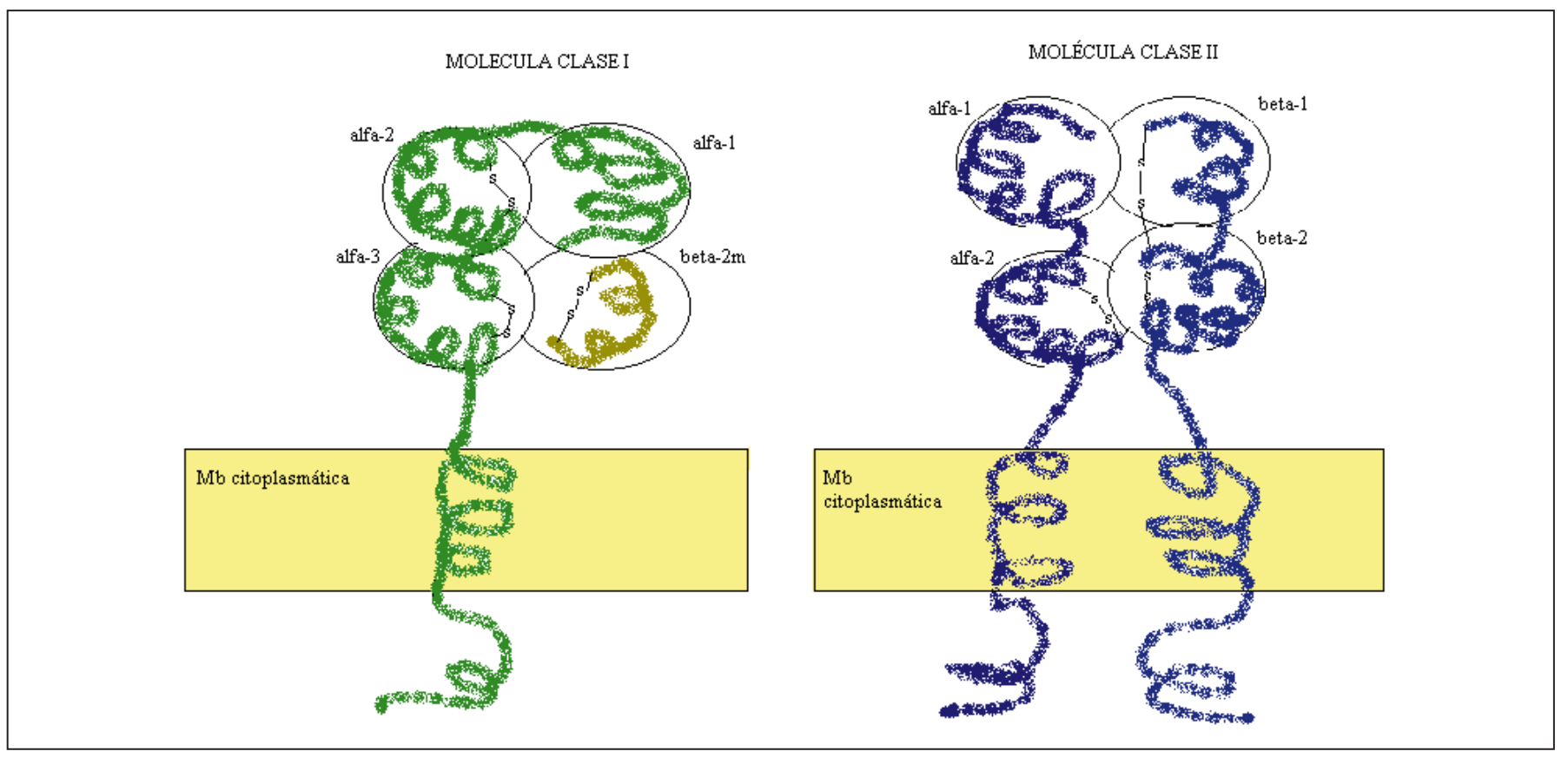

Figura 1. Estructura de las moléculas de clase I y II ${ }^{4}$. 


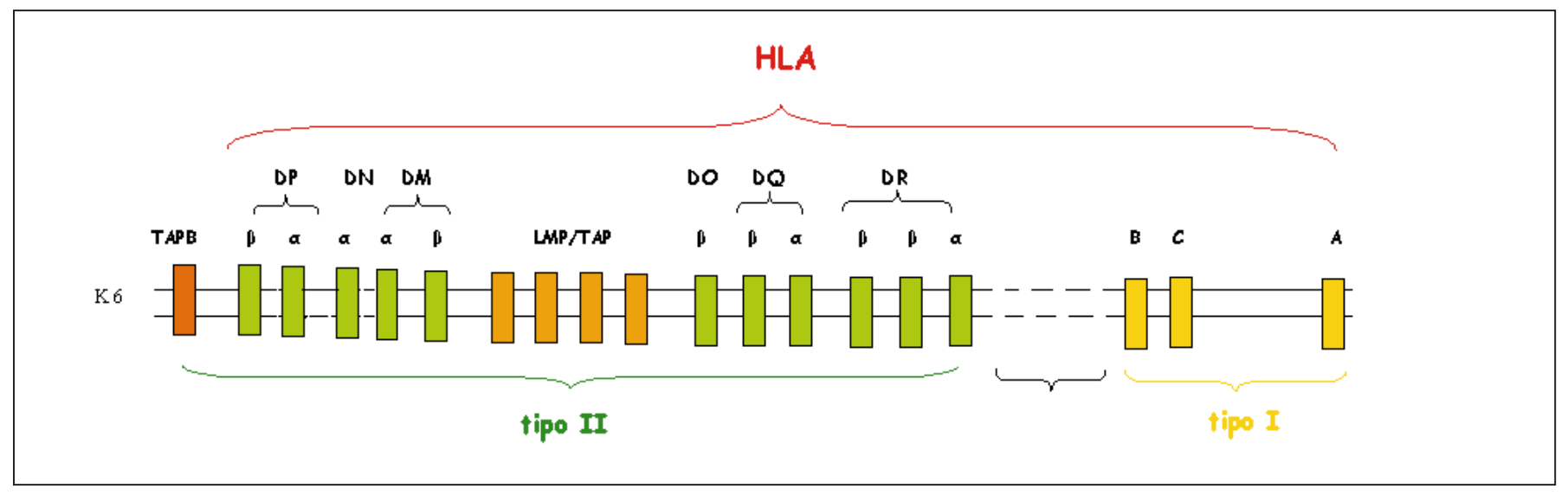

Figura 2. Genes del complejo HLA ${ }^{2}$.

Los dominios $\alpha 1$ y $\beta 1$ conforman esta vez la hendidura de unión al péptido y, de nuevo, son los sitios con principal polimorfismo, lo que define la especificidad antigénica.

Las diferencias fundamentales entre ambos tipos de moléculas radican en los extremos de la hendidura de unión al péptido ( más abiertos en la molécula de clase II) así los extremos de un péptido unido a la molécula de clase I se hallan más "enterrados" dentro de dicha molécula.

Podemos ver que en ambos casos, los dominios más cercanos a la membrana se asemejan a los dominios de inmunoglobulina mientras que difieren en los dominios distales destinados a crear una hendidura larga, lugar donde se une el péptido.

Sus estructuras diferentes les permiten realizar funciones distintas en la presentación de antígeno, unión de péptidos en sitios intracelulares diferentes y activación de poblaciones distintas de células, pero todo esto lo veremos con más detalle a continuación.

\section{B-GENÉTICA: ESTRUCTURA DEL CMH (fig.2).}

El complejo mayor de histocompatibilidad se extiende sobre aproximadamente 4 centimorgans de ADN ( $4 \times 10^{6}$ pares de bases) $y$, en humanos, contiene mas de 200 genes en el interior del complejo y alrededor. A medida que progresa la investigación para definir los genes del $\mathrm{CMH}$, es probable que vaya creciendo en número, estudios recientes sugieren que actualmente podría extenderse al menos $7 \times 10^{6}$ pares de bases.

Existen diferentes grupos de genes del sistema HLA entre los que se destacan los siguientes:

-Genes de HLA clase I: Existen tres loci o genes que se denominan respectivamente HLA A, HLA B, HLA C. Cada uno de ellos tiene varios alelos o formas del mismo gen.

-Genes de HLA clase II: Existen al menos tres loci en ellos, HLA DR, HLA DQ, HLA DP y todos ellos con sus alelos correspondientes. En muchos haplotipos del grupo HLA DR contiene un gen adicional de cadena bcuyo producto puede emparejarse con la cadena a.

-Genes de HLA clase III: Entre éstos se encuentran los genes que codifican los componentes del sistema del complemento, los TNF $\alpha$, TNF $\beta$ entre otros.

De todo lo expuesto, podemos deducir que los tres genes clase I $(A, B, C)$ y los cuatro de HLA clase II (DR, DR $\alpha, D P, D Q$ ) de cada cromosoma, expresan en el ser humano seis moléculas diferentes de clase I y ocho de clase II, además las combinaciones pueden aumentar para los genes de clase II por la combinación de los genes que codifican las cadenas $\alpha$ y $\beta$.

De este modo, éste complejísimo sistema puede caracterizarse por: 
-su alto polimorfismo: por la existencia de múltiples variantes de cada gen o alelos que difieren entre ellos en unos pocos aminoácidos y cada uno de ellos presenta una frecuencia relativamente elevada en la población.

-su gran poligenismo: existen diversos genes de HLA de clase I, II y III que codifican proteínas con diferentes espectros de especificidad. Su transmisión realizada de forma Mendeliana y la posible recombinación entre loci de distintos genes del mismo progenitor hace que un individuo presente una particular combinación de los alelos HLA en un simple cromosoma (haplotipo) diferenciándolo de otros, incluso entre hermanos.

Como hemos visto antes, todas las moléculas de MHC de clase I y II son capaces de presentar péptidos a las células $T$, pero cada proteína une un espectro diferente de péptidos, por tanto la presencia de los diferentes genes de cada clase de MHC implica que cualquier individuo está equipado para presenciar un abanico enormemente amplio de péptidos diferentes quedando aprovisionado de un número impresionante de especificidades antigénicas.

Aunque debemos destacar que existen determinados alelos que aparecen con más frecuencia que los esperados por el azar( su frecuencia de aparición juntos observada en un haplotipo determinado es mayor que la multiplicación de las frecuencias esperadas por separado). Cuando esto ocurre se dice que presenta un desequilibrio de unión (linkage desequilibrium).

\section{C-FUNCIONES DE LAS MOLÉCULAS DEL CMH.}

Como hemos ido introduciendo, la función fundamental de las moléculas del $\mathrm{CMH}$ es la de unirse específicamente a péptidos resultantes de la degradación de antígenos (que han penetrado dentro de las células presentadoras de antígenos, CPA) para posteriormente ser expresados en su superficie y que puedan ser reconocidos por las células $\mathrm{T}$ apropiadas ,uniéndose específicamente a ellas y ocasionando una cascada de acontecimientos que daría paso a una respuesta inmune adaptativa.
En ambas clases de moléculas del MHC, los péptidos unidos se encuentran rodeados como si de un sandwich se tratara dentro de la hendidura que conforman dichas moléculas, lo que provoca que el receptor de la célula $T$ interaccione estableciendo contactos tanto con la molécula de $\mathrm{MHC}$ como con el péptido antigénico.

\section{Función de las moléculas de clase I:}

Las moléculas de clase I se expresan en las membranas de todas las células nucleadas sin excepción, siendo las más importantes las células hematopoyéticas.

Dichas moléculas presentan en superficie antígenos (procesados previamente) que serán reconocidos únicamente por linfocitos T CD8+(citolíticos).

Procesamiento de los antígenos por las moléculas de clase I:

Los agentes patógenos (virus), penetran en las células nucleadas y, en su citosol, son degradados a partículas más pequeñas en un proteasoma. Las moléculas de tipo I, se hayan unidas a unas proteínas específicas (calnexina, calreticulina y tapasina) y retenidas en el retículo endoplásmico hasta que los péptidos procedentes del proteasoma se fijan a ellas. El complejo molécula HLA clase I-péptido es transportado al exterior de la célula en la membrana citoplasmática. Una vez allí, el linfocito TCD8 inactivo lo reconoce mediante su receptor específico y se activa de forma que pasa a ejercer una acción citotóxica a nivel de las células marcadas por al complejo molécula HLA I-péptido.

\section{$>$ Función de las moléculas de clase II:}

Estas, en cambio, se expresan únicamente en las células profesionales presentadoras de antígenos (células dendríticas, macrófagos, monocitos, linfocitos $\mathrm{B}$ y linfocitos $\mathrm{T}$ y NK activados) y presentaran en superficie antígenos que serán reconocidos únicamente por linfocitos TCD4+.

Los agentes patógenos que se unen específicamente 
con las moléculas de clase II son bacterias intracelulares, parásitos, bacterias extracelulares y toxinas.

\section{Procesamiento de los antígenos por las moléculas} de clase II:

La célula presentadora de antígeno (como el macrófago) ingiere una bacteria intracelular o una toxina que acaba degradándose a péptidos mas pequeños dentro de un compartimento intravesicular con un $\mathrm{pH}$ ácido. La molécula de clase II llega a éste lugar bloqueada por una proteína que es degradada en presencia de catalasas activas (captesina $\mathrm{S}$ o L) quedando un pequeño péptido unido a la hendidura. Junto al PH ácido y la ayuda de otra molécula de estructura similar a la molécula de clase II , liberan la hendidura de la molécula HLA de clase II y provoca que los péptidos específicos se unan a ella. El complejo molécula HLA-péptido es transportado hasta la superficie de la célula donde se une específicamente con los receptores de los linfocitos TCD4 activándolos y adquiriendo la capacidad de activar a más macrófagos (para destruir a más patógenos intracelulares) y a los linfocitos B secretores de inmunoglobulinas específicas.

\section{ASOCIACIÓN HLA Y ENFERMEDAD}

Ha sido frecuente la pretensión de asociar diferentes enfermedades a marcadores genéticos polimórficos. Basados en la primera descripción, a nivel experimental, hecha en 1996, sobre la relación existente entre la susceptibilidad al virus de Gross y el sistema HLA del ratón, comenzaron a buscarse diferentes asociaciones entre diferentes tipos de patologías y el polimorfismo HLA.

Así, durante los últimos veinte años las asociaciones HLA -enfermedad han ido desplazándose en función de los genes de HLA que se han ido describiendo.

Numerosas enfermedades se han asociado con el sistema HLA, en especial, enfermedades autoinmunes o con disfunciones inmunológicas, lo cual no es sorprendente debido a la función fundamental de los productos del sistema HLA en la regulación de la respuesta inmune.

\begin{tabular}{|l|c|c|}
\hline ENFERMEDAD & HLA & R.R \\
\hline Narcolepsia & DR2 & 30 \\
Espondilitis anquilosante & B27 & 69 \\
Enfermedad de Reiter & B27 & 37 \\
Enfermedad celiaca & DR3 & 12 \\
Síndrome de Good-Pasture & DR2 & 14 \\
Dermatitis herpetiforme & DR3 & 17 \\
Deficiencia de 21-OH & B47 & 10 \\
Hemocromatosis primaria & A3 & 7 \\
Diabetes M.I.D & DR4 /DR3 & $4 / 2$ \\
Artritis reumatoide & DR4 & 4 \\
Esclerosis múltiple & DR2 & 3 \\
\hline
\end{tabular}

Tabla 1. Asociación HLA y enfermedad. Ejemplos significativos con máximos RR.

La introducción de técnicas de biología molecular en la definición de los genes del HLA, ha permitido identificar con mayor exactitud los haplotipos asociados a enfermedades, los genes precisos inductores de la susceptibilidad a determinadas enfermedades, las posibles sustituciones de nucleótidos (en dichos genes) y sus consecuencias estructurales y funcionales sobre todo si se afectan la región más variable de la molécula resultante y al lugar de unión de los péptidos antigénicos.

En términos generales, distintos genotipos pueden conferir diferentes grados de riesgo a padecer una determinada enfermedad y, en ocasiones, es posible reconocer combinaciones alélicas que dan lugar a configuraciones determinadas de moléculas HLA determinadas implicadas en los mecanismos etiopatogénicos de ciertas enfermedades.

Los ejemplos mas significativos de asociación con al sistema HLA recaen en las siguientes enfermedades: Enfermedad celiaca, Dermatitis herpetiforme, Artritis reumatoide, Esclerosis múltiple, Diabetes M.I.D, Narcolepsia, Espondilitis anquilosante, Enfermedad de Reiter, Hemocromatosis primaria, Deficiencia de 21-OH (tabla 1) $(5,6)$.

Por otro lado, F. Femiano y col. (7) estudian una serie de enfermedades autoinmunes de la cavidad oral asociadas al HLA presentando un cuadro con las siguientes patologías: enfermedad de Behçet, pénfigo, penfigoide bulloso, psoriasis, liquen plano, síndrome de Sjögren y lupus eritematoso sistémico (tabla2). 


\begin{tabular}{|l|c|c|}
\hline ENFERMEDAD & HLA & R.R \\
\hline Narcolepsia & DR2 & 30 \\
Enfermedad de Behçet & B51 & 22,5 \\
Pénfigo & DR4 & 14,7 \\
Penfigoide bulloso & DQB1 & 4,3 \\
Psoriasis & Cw6 & 24,4 \\
Liquen plano & DR2 & 4,7 \\
Sindrome de Sjogren & Dw3 & 5,8 \\
Lupus eritematoso sistemico & DR3 & 2,6 \\
\hline
\end{tabular}

Tabla 2. Asociación HLA y enfermedades autoinmunes orales.

El espectro de entidades nosológicas en patología humana que han sido objeto de estudio tratando de encontrar una asociación con HLA es realmente exhaustivo...Esto queda además plasmado en nuestra literatura odontológica en la que actualmente encontramos algunos tipos de patología a la que se está empezando a asociar con el sistema HLA; en especial determinadas enfermedades orales de gran prevalencia pero aún poco estudiados en éste área como lo son la caries, los trastornos temporomandibulares y la enfermedad periodontal .Veremos a continuación de que forma los estudios del HLA se están introduciendo en la investigación de dichas enfermedades bucales.

\section{HLA Y CARIES}

De sobra se sabe que la caries dental es una enfermedad multifactorial, en la cual es necesario la aportación de hidratos de carbono como sustrato de los microorganismos y la presencia de otros muchos factores relacionados con el huesped y el hospedador. Todos estos factores podrían tener similar influencia en lo que respecta a su génesis y posterior desarrollo conlleva; pero esto no es así, ya que simplemente en lo que se refiere a factores individuales de riesgo o protección ya varía sustancialmente entre individuos lo que nos lleva a afirmar que todavía estamos lejos del conocimiento específico que diferencie a nuestros pacientes de alto riesgo de los de bajo riesgo...

Como decíamos anteriormente, la incidencia de la caries dental está afectada por una serie de factores del huesped tales como la estructura del esmalte dental, la respuesta inmunológica frente a bacterias cariogénicas o la composición de la saliva. Y, por lo tanto, las variaciones genéticas de dichos factores podrían contribuir a elevar el riesgo a la caries dental $(8,9)$.

Cada vez son más numerosos los estudios que han descrito una potente contribución genética en el riesgo a padecer caries dental. La bibliografía revisada nos delata que la genética y, particularmente el estudio del sistema del HLA, se está empleando en diversas líneas de investigación relacionándose con temas como la predisposición genética a acumular microorganismos cariogénicos, la posible vacuna contra la caries, el desarrollo de la respuesta inmune de la pulpa dental y su reacción ante determinadas situaciones como la caries.

\section{- Acúmulo de microorganismos orales: ¿predisposición genética?}

Con el fin de investigar la predisposición genética a acumular microorganismos orales, se examinó la relación entre el sistema de HLA de clase II y el número de S. Mutans y Lactobacilos en saliva en 102 adultos jóvenes en Japón. Los resultados sugirieron que determinados alelos del sistema HLA de clase II estaban relacionados con poblaciones salivares de microorganismos orales tales como los S. Mutans y Lactobacilos (10).

Igualmente, se estudió la asociación de genes del MHC con niveles de microorganismos cariogénicos y la severidad de caries en una población de mujeres americanas. Los resultados encontrados mantuvieron la hypótesis de la asociación entre determinados perfiles de HLA de clase II y TNF $\alpha$ y la colonización de S. Mutans, L.Casei y L. Acidophilus como patógenos involucrados en la etiología de las caries 11 .

Siguiendo ésta misma línea, quisieron comprobar la relación existente entre las moléculas de HLA-DR4 y el número de estreptococos en saliva en estudiantes de odontología y personal docente en la universidad de Lund, Suecia. Los resultados en cuanto a la tendencia de asociación encontrada entre el HLA DR4 y altos niveles de S.Mutans no fue estadísticamente significativa. No se tuvo en cuenta la influencia de los 
conocimientos que los individuos expuestos al estudio (todos relacionados con la profesión) pudiesen tener previamente para minimizar el riesgo de caries y el número de $\mathrm{S}$. Mutans (12).

Más tarde, éste mismo equipo llevó a cabo un estudio en el que quisieron describir y comparar la reacción de la inmunoglobulina A (IgA) ante Estreptococos orales en individuos HLA DR4-positivos y HLA DR4-negativos. Se encontró una gran variabilidad en cuanto a la correlación que existía entre la colonización de S. Mutans (baja actividad de la IgA) y los sujetos HLA DR4 positivos pero ésto podía ser el resultado de la alta heterogenicidad existente en este grupo de sujetos, por lo tanto, la relación sólo podía demostrarse a nivel de subgrupos de HLA DR4 (DRB1*04, DRB1*01) (13).

\section{$>$ Vacuna contra la caries}

Con el ánimo de investigar una posible vacuna contra la caries, otra serie de estudios han intentado identificar los diferentes antígenos provenientes de Estreptococos que pudiesen estar vinculados con moléculas del sistema HLA de clase II. Para ello, se han utilizado distintos antígenos en vacunas experimentales contra la caries, como los carbohidratos de superficie (que diferencian el S. Mutans de los siete serotipos), las proteínas de la pared celular, la glucosiltransferasa (GTF) y otros antígenos (dextranos, ácido lipoteicoico, polisacáridos extracelulares purificados...) $(8,14)$.

Así, Sempuku, H y col. (15) iniciaron el estudio del antígeno PAc (proteína de superficie del S. Mutans) y su asociación con el sistema HLA de clase II (HLA DR) y sugirieron que una vacuna fabricada con dicho péptido podría ser efectiva en humanos y podría ser diseñada combinando las múltiples asociaciones con los epitopos de células B hasta producir un único anticuerpo contra la caries.

A éste lo siguen Nomura y col. (16) que, ya en 2002, trataron igualmente de identificar antígenos de $\mathrm{S}$. Mutans (específicamente la glucosiltransferasa y la PAc) que interaccionaban con el sistema de HLA DR8 sugiriendo igualmente dichos antígenos como posibles componentes de una vacuna efectiva para la caries .

\section{$>$ El papel de la respuesta inmune de la pulpa ante determinadas situaciones}

Sabemos que las células que expresan en su superficie las moléculas del HLA de clase II están generalmente asociadas con las fases tempranas de la respuesta inmune. Algunos estudios se han centrado en analizar la distribución de éstas células en diferentes situaciones de desarrollo del diente, así como en dientes cariados para así esclarecer en qué momento la pulpa adquiere una defensa inmunológica potente y cómo reacciona ante una caries.

Así, autores confirman que una respuesta inmune alterada frente a las bacterias cariogénicas podría incrementar la incidencia de caries pero que aun así, la evidencia que sostiene una posible herencia de la susceptibilidad dental a la caries es limitada y que la asociación entre la herencia de determinados patrones de HLA y el riesgo a caries es débil por lo que no se puede establecer ninguna base para predecir un futuro riesgo de caries (9).

Las moléculas del sistema del MHC de clase II expresadas en las células se encuentran distribuidas en la pulpa dental y se ha demostrado que se acumulan alrededor de la lesión cariosa (17). Un estudio analizó la relación existente entre el sistema HLA de clase II de células dendríticas presentadoras de antígenos y las respuestas de las fibras nerviosas ante cavidades, caries o tratamiento dental. Los resultados indicaron que existían diferentes respuestas inmunológicas de la pulpa cuando ésta se exponía diferentes situaciones: preparación cavitaria y restauración en condiciones normales o cariosas. Además, se vió que dicha respuesta duraba varios meses incluso tras el tratamiento (18). Luego, si el sistema HLA juega un papel importante en cuanto a la regulación de la respuesta inmunológica ante una agresión del esmalte dental, porqué no pensar que éste pueda predisponer al individuo a una mejor o peor respuesta a la caries?

La expresión de moléculas del sistema HLA de clase II en la pulpa de dientes deciduos a punto de perderse, fue objeto de estudio de Kannari, N y col. (19). Mediante métodos inmunohistoquímicos y usando anticuerpos monoclonales anti- HLA DR, estudiaron la distribución de la expresión de dicho complejo en 
células de la pulpa en los dientes deciduos durante el proceso de reabsorción fisiológica de la raíz. Concluyeron que las células HLA DR inmunopositivas de la zona coronal de la pulpa juegan un papel importante en la diferenciación, migración y/o activación de los odontoclastos y cementoclastos durante la etapa de reabsorción radicular.

Tras ésta revisión bibliográfica que relaciona el estudio del sistema HLA y la caries y basándonos en el estudio realizado por Yoshiba (20), podríamos concluir que la pulpa dental está equipada con una potencial defensa inmunológica antes de la erupción, que en la etapa inicial de la infección por caries se inicia una respuesta inmunológica mediada por células que expresan moléculas del sistema HLA ce clase II, y que las células HLA DR positivas invaden los túbulos dentinarios en su profundidad a medida que la lesión cariosa avanza.

\section{HLA Y DESÓRDENES TEMPOROMANDIBULARES}

Los desórdenes temporomandibulares se han identificado como una amplia categoría que incluye la disfunción de las estructuras esquelético-musculares de cabeza y cuello y de la articulación temporomandibular (ATM).

La literatura sobre los trastornos del sistema masticatorio se ha incrementado de manera espectacular a partir de la década de los ochenta, pero ello no nos ha esclarecido un mejor conocimiento etiopatogénico de dichos desórdenes, en cambio, si se ha subrayado la compleja, hetereogénea y multifactorial naturaleza de aquéllos.

Como sabemos, no hay una etiología única que explique todos los signos y síntomas derivados de dicha alteración(dolor, disfunción y ruidos articulares fundamentalmente); existen una serie de factores de riesgo potenciales que han sido tradicionalmente involucrados junto a la patología articular: las parafunciones (bruxismo), las interferencias oclusales y los factores emocionales y genéticos.

Cabe destacar la importancia que asume la toleran- cia fisiológica de cada individuo en esta patología, ésta hace que no todos respondan de la misma forma ante un mismo hecho. Así, cada paciente posee determinadas características peculiares que definen su constitución, en las que influyen factores locales (como la estabilidad ortopédica) y factores sistémicos entre los que nos encontramos elementos genéticos, tema abordado en éste estudio $(21,22)$.

Retomando nuestra línea de interés, y basándonos en la bibliografía más actual, veremos de qué manera el estudio del HLA ha servido en el campo de investigación de los desórdenes temporomandibulares.

Algunos autores sostienen que es improbable que la respuesta inmune juegue un rol primario importante en el inicio de la inflamación sinovial y destrucción del cartílago en pacientes con desórdenes temporomandibulares, en cambio, sí que adquiere importancia en cuanto al mantenimiento y severidad. Así lo afirman Fu y col. (23), que estudiaron la expresión del HLA-DR y la interleukina-6 en el liquido sinovial de los pacientes con disfunción temporomandibular y observaron que el estudio inmunohistoquímico mostraba claramente una presencia significativamente alta de células que expresaban HLA-DR en el liquido sinovial.

Por otro lado, Halpern y col. (24) declaran que la utilización de marcadores genéticos, tests serológicos, y la minuciosa elaboración de una historia médica y quirúrgica podrían guiar al clinico a determinar qué pacientes serían mejores candidatos para el tratamiento quirúrgico de tratornos temporomandibulares. En un estudio, utilizaron los métodos diagnósticos anteriormente citados en tres grupos de pacientes con diferentes grados de alteración temporomandibular, desde estadios tempranos e intermedios hasta estadios tardíos y graves. Los tests serológicos que utilizaron incluían la determinación de subtipos de HLA que fueron significativamente diferentes en los tres grupos de pacientes .

Hemos de destacar que dentro de las enfermedades asociadas al HLA nos encontramos con enfermedades que afectan especialmente a la articulación temporomandibular: la Artritis Reumatoide relacionada con HLA de tipo I y la Espondilitis Anquilosante relacionada con HLA de tipoII. 


\section{$>$ HLA y la Espondilitid Anquilosante (EA)}

La Espondilitis Anquilosante tiene una incidencia del $1 \%$ en poblaciones caucásicas y ha sido descrita asociada con la presencia de HLA-B27 en un 95\% de los enfermos, siendo la frecuencia de dicho antígeno en individuos sanos del 3\% al $7 \%$.

La presencia de dicho antígeno es empleado como dato confirmatorio ante la sospecha de la enfermedad, pero no puede considerarse como un marcador diagnóstico, ya que a pesar de su elevada frecuencia en los enfermos, solamente un $2 \%$ de los individuos B-27 positivos la desarrollan, aumentándose al $20 \%$ cuando existen antecedentes familiares. Por otra parte, existen pacientes de Espondilitis Anquilosante B-27 negativos e importantes variaciones de frecuencia según la etnia de la población afectada (en negros americanos sólo el $50 \%$ de enfermos son B27 positivos) lo que le resta protagonismo a esta destacable asociación que continúa siendo un enigma.

Henry y col. (25) realizaron un estudio en el que, basándose en la hipótesis de la asociación de la E.A. con una determinada bacteria ("mimetismo molecular": antisueros anti-bacterias tendrían reactividad cruzada con células HLA-B27 positivas), realizaron el análisis del HLA en pacientes con trastornos internos de la ATM. Éstos encontraron que no sólo existía una reacción de la enfermedad con los antígenos HLAB7 (reacción cruzada), sino que también existía un riesgo en pacientes con diversos alelos del HLA de tipo I (-A1, -A2,-A3,-B7,-B14,-B35,-B44) y de tipo II (-DR1,-DR4) a desarrollar trastornos de la ATM como consecuencia de determinados agentes bacterianos.

\section{> HLA y la Artritis Reumatoide (AR)}

Una de las relaciones mas complejas descritas es la existente entre la Artritis Reumatoide (AR) y el sistema mayor de histocompatibilidad. Al tratar de investigar en la etiología de la AR, siempre fueron objeto de estudio otros aspectos inmunopatogénicos, aparte de su asociación, no unívoca a un determinado alelo HLA, dependiendo de otros factores (edad de aparición, factor reumatoide etc.). Se refleja así la interrelación de diversos mecanismos en su patogenia, resaltándose la responsabilidad de una deficien- te presentación de un peptido artritogénico por parte de la molécula HLA.

La asociación más relevante se observa con un incremento en la frecuencia de DR4 (63\%-85\% en los enfermos). Aunque esta asociación es incompleta pues no todos los haplotipos que llevan HLA-DR4 se asocian a AR. Además existen determinados subtipos más ligados que otros que varían, además, entre diferentes grupos étnicos. En cuanto al caso de la AR juvenil, se vio que la asociación se daba con el HLADR5 (DR11 y DR12) y HLA.DR8, además de otras dos regiones en MHC (-DP y A2 ). La influencia de estos marcadores de HLA sería de independencia unos de otros pero la susceptibilidad para la enfermedad es frecuentemente debida a los dos haplotipos.

Con el objeto de estudiar los factores de riesgo que influyen para que se de una erosión condilar en pacientes con artritis juvenil, Petersen y col. (26) evaluaron el impacto de determinadas variables como el sexo, tipo de comienzo, transcurso y desarrollo de la artritis juvenil, edad de comienzo, así como el estado del HLAB27, anticuerpos antinucleares(ANA),y factor reumático en dichos pacientes. Dentro de los resultados hallados, se encontró que los pacientes HLA-B27 positivos presentaban un bajo riesgo de trastornos temporomandibulares y cambios erosivos en el cóndilo.

Por otro lado, Karhulahti y col. (27) tras un estudio de las erosiones condilares relacionadas a la edad, comienzo y subtipos de Artritis Reumatoide en niños de 15 años, declaraba que factores como la presencia del alelo HLA-B27, factor reumático o anticuerpos antinucleares por si solos no se mostraban asociados con el riesgo a padecer alteraciones de la ATM.

El breve repaso presentado deja claro que el estudio del HLA no sólo se ha empleado en investigaciones relacionadas con estos dos tipos de enfermedades multisistémicas, que, al fin y al cabo, son muy específicas y se dan en un porcentaje muy bajo de la población $(0,1 \%$ para la EA y $0,8 \%$ para la A:R). Se ha demostrado que el análisis del HLA puede tener utilidad en el campo de la etiopatogenia de las disfunciones y alteraciones temporomandibulares, el cual sigue siendo un enigma sin resolver, así como en la evolución y planificación del tratamiento. 


\section{HLA Y ENFERMEDAD PERIODONTAL}

Las enfermedades periodontales incluyen todos los trastornos de las estructuras de soporte de los dientes. Son procesos infecciosos que presentan una serie de características específicas; no la producen una sola bacteria sino que pueden ser varias las implicadas y, aunque existen bacterias especialmente periodontopatógenas, muchas forman parte de la flora residente.

Aunque las bacterias son el factor etiológico primario en las enfermedades periodontales, la respuesta del hospedador es un determinante de la susceptibilidad de la enfermedad y, cada día, está cobrando más importancia. Por tanto, podríamos decir que las bacterias de la placa subgingival son la causa necesaria para que se dé la enfermedad pero no son suficientes por sí mismas.

Al igual que ocurre con la caries, las causas de ambas son multifactoriales más que específicas y se les puede aplicar un modelo etiológico según el cual son tres los componentes que forman la matriz etiológica: La virulencia del microorganismo, la resistencia o susceptibilidad del hospedador y las condiciones medioambientales (28).

Como decíamos antes, cada vez cobran más importancia los denominados factores de riesgo del hospedador. Éstos van a modular la susceptibilidad o resistencia del hospedador a padecer una periodontitis destructiva. Por lo tanto, nos vamos a encontrar con una serie de factores de riesgo: locales y sistémicos que nos pueden influenciar en la aparición y desarrollo de la enfermedad periodontal. Dentro de los factores sistémicos, tenemos una serie de factores genéticos que nos resultan interesantes en vista del tema que llevamos abordando desde el inicio de éste estudio.

La evidencia de que los aspectos genéticos juegan un papel en el comienzo y severidad de la periodontitis está aumentando en los últimos tiempos. Los métodos para determinar el riesgo genético de las periodontitis son de tres tipos: estudio de gemelos mono y dicigóticos criados juntos o por separado, estudios realizados en familias con periodontitis de inicio precoz y la asociación de las periodontitis con determinados desórdenes genéticos. La influencia de los factores genéticos parece ser diferente para los distintos tipos de enfermedad periodontal (29).

Se han propuesto numerosas hipótesis que implican a los factores genéticos; y, entre éstas, nos encontramos con la asociación de periodontitis con fenotipos determinados del HLA (American Academy of Periodontology 1999). Numerosos estudios han afirmado la contribución del sistema HLA como un factor genético potencial en la etiopatogénesis de la enfermedad periodontal $(30,31,32,33,34,35)$. Ya desde 1990 , Izumi y col. comentaron que si antígenos HLA están asociados a la susceptibilidad o resistencia de determinadas enfermedades, porqué no podrían estarlo a las enfermedades periodontales?

Las investigaciones más recientes afirman que la susceptibilidad o resistencia tanto de la periodontitis crónica como de la agresiva podría estar influenciada por determinadas combinaciones de antígenos del HLA (36).

De todos modos, el sistema del HLA es un eje de investigación poco explorado dentro de los numerosos estudios realizados sobre las diversas facetas inmunológicas de las periodontitis. La literatura cuenta con algunos resultados aparentemente divergentes y poco compatibles con una síntesis coherente. Sería necesario profundizar mas en el tema para poder extraer datos y conclusiones más relevantes lo que esperamos hacer en un próximo trabajo.

\section{BIBLIOGRAFÍA}

1. Janeway Jr. El complejo mayor de histocompatibilidad y sus funciones. En: Janeway, Jr. Inmunobiología. El sistema inmunitario en condiciones de salud y enfermedad. Masson. $2^{\text {a }}$ edición, 2003: 155-82.

2. Ortega Páez E. Estudio del polimorfismo HLA genómico y alteraciones orales en pacientes con enfermedad celiaca y familiares de primer grado. Tesis doctoral, julio 2003. 
3. Dausset, J. The mayor histocompatibility complex in man past, present and future concepts. Nobel Lecture. 8 December, 1980.

4. Blase, D. Les HLA: Revue des connaissances actuelles et perspectives en parodontologie. J Parodontol: 1989; 8: 7-29.

5. Kreisler, J.M.; Moreno, M.E. HLA y enfermedad. En: Peña Martinez J. Inmunología clínica. Bases moleculares y celulares. Arán. $2^{\text {a }}$ edición, 2001: 247-58.

6. Izumi, Y. Association HLA/maladies parodontales. J Parodontol. 1990; 9: 145-9.

7. Femiano, F. HLA e malattie autoimmuni del cavo orale. Minerva Stomatol, 2001; 50: 21-30.

8. Garcillán MaR. "Factores de riesgo de la caries dental". En: Rioboo, R. Odontología preventiva y odontología comunitaria. $1^{\text {a }}$ edición, 2002. Tomo I: 301-27.

9. Shuler, CF. Inherited risks for susceptibility to dental caries. J Dent Educ. 2001; 65: 1038-45.

10. Ozawa, Y. HLA class II alleles and salivary numbers of mutans streptococci and lactobacilli among young adults in Japan. Oral Micr Immunol. 2001; 16: 353-7.

11. Acton, RT. Associations of MHC genes with levels of caries inducing organisms and caries severity in African-American women. Human Inmunol. 1999; 60: 984-9.

12. Wallengren, M.L. HLA and number of mutans streptococci in saliva among dental students and staff. Acta Odont Scan. 1997; 55: 296-8.

13. Wallengren, M.L.. HLA-DR4 and salivary immunoglobulin A reactions to oral streptococci. Oral Micr Immunol. 2001; 16: 45-53.

14. Lehner T. Inmnumology of periodontal disease. Inmunology of dental caries. In: Lehner $\mathrm{T}$. Inmunology of oral diseases. Blackwell scientific publications. $3^{a}$ edición, 1992: 48-101.
15. Senpuku, H. Identification of Streptococcus mutans Pac peptide motif bindind with human MHC class II molecules (DRB1*0802,*1101, *1401 and *1405). Immunol. 1998; 95: 322-30.

16. Nomura Y. Identification of the peptide motifs that interact with HLA-DR8(DRB1*0802) in Streptococcus mutans proteins. Oral Microb Immunol. 2002; 17: 209-14.

17. Sakurai, K. Co-increase of nerve fibers and HLADR-and/or factor-XIIla-expressing dendritic cells in dentinal caries- affected regions of the human dental pulp: an immunohistochemical study. J Dent Res. 1999; 78: 1596-608.

18. Yoshiba, K. Class II antigen-presenting dendritic cell and nerve fiber responses to cavities, caries, or caries treatment in human teeth. J Dent Res. 2003; 82: 422-7.

19. Kannari, N. Class II MHC antigen-expressing cells in the pulp tissue of human deciduous teeth prior to shedding. Arch Histol Cytol. 1998; 61: 1-15.

20. Yoshiba, N. Immunohistochemical localization of HLA-DR-positive cells in unerupted and erupted normal and carius human teeth. $J$ Dent Res. 1996; 75: 1585-9.

21. Rioboo R. Estudio epidemiológico de las enfermedades y alteraciones bucodentales: patrones cambiantes y tendencias. Epidemiología de las alteraciones de la A.T.M. En: Rioboo, R. Odontología preventiva y odontología comunitaria. $1^{a}$ edición, 2002. Tomo II: 1071-83.

22. Okesson, DMD; Jeffrey P. Etiología de los trastornos funcionales del sistema masticatorio. En: Okesson, DMD; Jeffrey P. Tratamiento de la oclusión y afecciones temporomandibulares. Harcourt Brace. $4^{a}$ edición: 149-79.

23. Fu, K. Interleukin-6 in synovial fluid and HLA-DR expresion in synovium from patients with temporomandibular disorders. J Orofacial Pain: 1995: 9 (2): 131-7.

24. Halpern, L R. Temporomandibular disorders: cli- 
nical and laboratory analyses for risk assessment of criteria for surgical therapy, a pilot study. J Craniomand Pract: 1998: 16 (1): 35-43.

25. Henry, -C-H. Analisis of human leukocyte antigens in patients with internal derangement of the temporomandibular joint. J-Oral-MaxillofacSurg: 2002 Jul: 60 (7): 778-83.

26. Pedersen, T K. Resorption of the temporomandibular condylar bone according to subtypes of juvenile chronic arthritis. J Rheumatol: 2001 Sep: 28 (9): 2109-15.

27. Karhulahti, -T. Mandibular condyle lesions related to age at onset and subtypes of juvenile rheumatoid arthritis in 15-year-old children. Scand-JDent-Res.1993 Oct: 101 (5): 332-8.

28. Bascones A. Mecanismos inmunológicos de las enfermedades periodontales y periimplantarias. Av. Odontoestomatol. 2003; 19-3.000-000.

29. Rioboo, R. Estudio epidemiológico de las enfermedades y alteraciones buco-dentales: Patrones cambiantes y tendencias. Epidemiología de la enfermedad periodontal. En: Rioboo, R. Odontología preventiva y odontología comunitaria. $1^{\mathrm{a}}$ edición, 2002. Tomo II: 995-1043.

30. Nares, S. The genetic relationship to periodontal disease. Periodontol 2000. 2003; 82: 36-49.
31. Machulla HKG. HLA, B, Cw, DRB1, DRB3/4/5, DQB1 in German patients suffering from rapidily progressive periodontitis (RPP) and adult periodontitis (AP). J Clin Periodontol 2002; 29: 573-9.

32. Schenck, K. Procedings of the conference "New Frontiers in Oral Immunological Diseases", Lillehammer, Norway, 2001, Part I. Acta Odontol. Scand. 2001: 59: 120-4.

33. Tatakis D.HLA-27 transgenic rats are susceptible to accelerated alveolar bone loss. J Periodontol. 2000; 71: 1395-9.

34. Reyes-Botella, C. Expression of molecules involved in antigen presentation and $\mathrm{T}$ cell activation (HLA-DR, CD80, CD86, CD44, and CD54) by cultured human osteoclasts. J Periodontol; 2000; 71: 614-7.

35. Mouynet, P. Aspects immunologiques des problèmes buccodentaires. Encycl Méd. Chir (ParisFrance),Stomatologie-Odontologie I, 1995; 22009-T-10, 15 p.

36. Stein, J. Are there HLA combinations typical supporting for or making resistant against aggressive and/or chronic periodontitis?. J Periodontol Res. 2003; 38: 508-17. 